\title{
Primary central nervous system lymphoma: what a neurologist/neurosurgeon should know?
}

\author{
Linfoma primário de sistema nervoso central: o que um neurologista/neurocirurgião deve saber? \\ Guilherme Fleury Perini, Paulo Vidal Campregher, Fabio Pires de Souza Santos, Nelson Hamerschlak
}

\begin{abstract}
Primary central nervous system lymphoma is a rare disease, with bad prognosis. Neurologists and neurosurgeons should be familiar with the diagnostic, and biologic features, as well as the initial management of patients. A correct approach to these patients is mandatory for a better outcome.
\end{abstract}

Key words: primary central nervous system lymphoma, neurologist, neurosurgeon.

RESUMO

Linfoma primário do sistema nervoso central é uma doença rara, com prognóstico ruim. Neurologistas e neurocirurgiões devem estar familiarizados com os aspectos do diagnóstico, características biológicas e do manuseio inicial dos pacientes. A abordagem correta desses pacientes é essencial para obter melhores resultados.

Palavras-Chave: linfoma primário de sistema nervoso central, neurologista, neurocirurgião.

The term primary central nervous system (CNS) lymphoma currently refers to lymphomas that arise exclusively in the CNS, including brain parenchyma, spinal cord, eyes, cranial nerves and meninges ${ }^{1}$.The diagnosis and treatment of this entity is peculiar, since it involves different medical specialties such as neurologists, neurosurgeons, ophthalmologists, oncohematologists and radiotherapy doctors. Therefore, all physicians involved should be familiar with basic information about the disease. In this article, we will focus on what a neurologist or neurosurgeon should know about CNS lymphoma and how they can help in the diagnosis and treatment.

Primary CNS lymphoma is a rare neoplasm with a dismal prognosis

Primary CNS lymphoma is a rare neoplasm, representing $4 \%$ of intracranial neoplasms and $4-6 \%$ of extra-nodal lymphomas. Annual incidence of this entity is about 0-5 cases per 100,000 people ${ }^{2}$. Most cases in immunocompetent patients are diagnosed in the fourth to seventh decade of life, with median diagnosis age in the fifth decade, men and women being equally affected ${ }^{3}$. There has been an increase in the incidence of primary CNS lymphoma from the 1960s to the 1990s, but since then, it has been showing a decrease ${ }^{4}$.

Immunodeficiency is the most important risk factor. In patients with acquired immunodeficiency syndrome (AIDS), the most common type of CNS tumor is lymphoma. However, other forms of immunodeficiency are also related to a higher incidence, including iatrogenic immunosuppression, Wiskott-Aldrich syndrome and common variable immunodeficiencies 5 . In this scenario, association with the EpsteinBarr virus is common.

The outcomes of primary CNS lymphoma treatments remain unsatisfactory, especially compared with patients with extra-CNS lymphomas with similar staging and histiotype. The mean survival of patients is reported to be 40 to 50 months, when treatment is based on a combination of chemotherapy and radiotherapy. A score for prognosis in such cases has been developed by the International Extranodal Lymphoma Study Group (IELSG), and is based on five risk factors:

1. Age $>60$ years;

2. Eastern Cooperative Oncology Group (ECOG) performance status $>1$;

3. High serum level of lactate dehydrogenase; 
4. High cerebrospinal fluid (CSF) protein concentration;

5. Involvement of deep regions of the brain (periventricular regions, basal ganglia, brainstem, and/or cerebellum).

In the original cohort of 105 patients $^{6}$, two-year survival rates were 80,48 and $15 \%$ for patients with $0-1,2-3$ and $4-5$ risk factors, respectively.

\section{The importance of differentiating primary from secondary CNS lymphoma}

The main part of the initial evaluation of a patient with primary CNS lymphoma is to exclude the hypothesis of a systemic lymphoma with secondary CNS involvement. It is known that specific subtypes of systemic lymphoma are more prone to involve CNS, such as primary testicular lymphoma ${ }^{7}$ and refractory primary mediastinal lymphoma. Recently, it has been reported that patients with systemic lymphoma compromising the kidneys account for a higher incidence of CNS involvement ${ }^{8}$. It is mandatory to exclude systemic lymphoma, for prognosis and treatment of these two entities are completely different.

Therefore, the initial evaluation of a patient with suspected primary CNS lymphoma includes computerized tomography (CT) scan of the neck, chest, abdomen and pelvis. Finding of enlarged lymph nodes or extranodal masses must be evaluated by biopsy. Positron emission tomography (PET-CT) scan is a method that can be used to exclude this hypotesis, but there are some limitations such as availability and financial resources. It is also recommended that male patients older than 60 years that cannot be evaluated by PET-CT should be submitted to testicular ultrasonography ${ }^{9}$, due to a high incidence of CNS involvement in primary testicular lymphoma. Bone marrow biopsy is also necessary to exclude bone marrow infiltration.

The second part of the initial evaluation is the study of the extension of the disease in the CNS. For this purpose, whole brain magnetic resonance imaging (MRI), CSF cytology and biochemical examination, and ophthalmologic evaluation including slit-lamp examination are necessary. CSF cytology is important, because the CSF may function as a "sanctuary" reservoir for lymphoma cells, and higher doses of chemotherapy or direct delivery of chemotherapy may be necessary. Since $18 \%$ of patients have CSF involvement when evaluated by flow cytometry, whenever possible, CSF should be studied with this technique ${ }^{10}$.

An ophthalmic evaluation with slit-lamp examination is also essential because about $15-25 \%$ of patients present concomitant ocular involvement ${ }^{11}$. Eyes also function as a sanctuary, and patients with ocular involvement should be evaluated for ocular radiotherapy, and vitrectomy and corticosteroids as part of their treatment. More interestingly, some patients with PCNSL complain of a previous history of uveitis or other ocular conditions. Nevertheless, these patients may in fact have a primary intraocular lymphoma with secondary brain involvement rather than PCNSL.

It is also important to evaluate the overall condition of the patient to plan the adequate treatment. Baseline evaluations of renal, hepatic and heart function are necessary to predict complications and adjust chemotherapy doses 9 . Hepatitis B, C and HIV serology may contribute for the treatment of these conditions (HAART) or to help prevent complications associated with biological agents (rituximab). A complete baseline neuropsychiatric assessment is also important to evaluate long-term complications of therapy.

\section{Not all vanishing tumors are primary CNS lymphoma}

Since most patients $(60 \%)$ present with a brain parenchyma mass, it is expected that some of them present with symptoms of augmented intracranial pressure. Instinctively, most physicians will consider the use of corticosteroids as part of the initial treatment of brain edema. However, the primary CNS lymphoma is extremely sensitive to high doses of corticosteroids, and up to $40 \%$ of patients may have significant shrinkage or even total disappearance of lesions ${ }^{12}$. This condition has been referred to as "vanishing tumor" syndrome. Two questions arise when one consider using corticosteroids to treat a patient with suspected primary CNS lymphoma: can one safely manage a stable patient with brain mass and edema without corticosteroids? And can all vanishing tumors be considered a case of primary CNS lymphoma?

With recent advances in CNS imaging, a presumptive diagnosis of this entity can usually be made by MRI and complementary techniques, such as SPECT. When this is the main hypothesis, and if patients are stable with no life-threatening edema, the use of corticosteroids should be limited. The use of corticosteroids may impair the acquirement of material and can even interfere in histopathologic diagnosis ${ }^{13}$. If patients are already on steroids, the interruption of therapy 7-10 days before biopsy should be considered in order to improve diagnosis, unless a MRI-confirmed progression on steroids is observed.

Assuming a vanishing tumor as a primary CNS lymphoma is erroneous. A variety of conditions is steroid-sensitive and may present with symptoms and radiographic findings compatible with this hypothesis. Sarcoidosis, multiple sclerosis, acute encephalomyelitis, and other malignancies can also exhibit a dramatic response to steroids $^{14}$. In our institution, when a brain mass disappear after the administration of steroids, we recommend waiting for recurrence, and we start chemotherapy only after confirmed histhopatologic diagnosis. 


\section{Complete resection of lesions is unnecessary and probably harmful}

Whenever neuroimaging suggests primary CNS lymphoma, stereotactic-guided biopsy is the method of choice in establishing the definitive diagnosis ${ }^{9}$. Aggressive surgical resection is not necessary, and can be even harmful for the patients. In a meta-analysis of 50 published prospective and retrospective series, aggressive resection failed to improve survival, but was also responsible for chemotherapy delay ${ }^{15}$. Moreover, since PCNSL shows dramatic responses to chemotherapy or corticosteroids, a complete resection may result in neurological impairment, due to unnecessary resection of surrounding brain parenchyma.

However, the diagnosis not always can be suspected by neuroimaging. In patients with radiologic suspicion of other brain tumors or metastasis, complete resection is routinely performed, sometimes resulting in an unexpected diagnosis.

\section{Treatment of primary CNS lymphoma is different from systemic lymphoma}

Although chemotherapy is a main part of the treatment, it should be noted that drug efficacy is limited by several factors, including the effect of the blood-brain barrier (BBB) in blocking the diffusion of drugs to the CNS. When treating a patient with primary CNS lymphoma, it should be emphasized that drug delivery to CNS is not homogeneous. In fact, drugs can be divided in three groups: 1) drugs with poor BBB penetration that cannot be escalated to high doses due to dose-limiting toxicity (anthracyclines, vinca-alkaloyds); 2) drugs exhibiting low to moderate capability to cross that $\mathrm{BBB}$, that can be escalated to doses that penetrate the BBB (methotrexate (MTX), cytarabine); 3) drugs that naturally penetrate de BBB in conventional doses (steroids, some alkylating agents like temozolomide, thiotepa and nitrosureias) ${ }^{16}$.

Treatment of systemic lymphoma is usually based in drugs from group 1. For this reason, treating patients with primary CNS lymphoma with classic regimens for lymphoma (e.g. cyclophophamide, doxorubicin, vincristine and prednisone - CHOP), has shown very low response rates ${ }^{6}$. The treatment of primary CNS lymphoma is based mainly on drugs from groups 2 and 3. In fact, the backbone of primary CNS lymphoma treatment is based on MTX and cytarabine.

MTX, an antifolate drug has shown great anti-lymphoma effect and is used in classic regimens for aggressive lymphomas. MTX inhibits dyhidrofolate reductase, an enzyme that participates in the tetrahydrofolate synthesis. Drug levels over $1 \mathrm{~g} / \mathrm{m}^{2}$ safely penetrates the brain parenchyma, and levels over $3 \mathrm{~g} / \mathrm{m}^{2}$ lead to adequate concentration in the $\operatorname{CSF}^{17-19}$. For this reason, it has been proposed that in patients receiving $3 \mathrm{~g} / \mathrm{m}^{2}$ or more, intrathecal chemotherapy could be used more cautiously ${ }^{20}$. In patients receiving high doses of MTX, it is necessary to promote urine alkalynization and folinic acid rescue, in order to augment the MTX elimination and lessen its toxicity.

Cytarabine, a pyrimidine analog is also used as part of PCNSL treatment. In fact, the first prospective trial evaluating the treatment of PCNSL was designed to evaluate the efficacy of adding cytarabine to high-dose MTX and showed that the addition of cytarabine to high-dose MTX improves overall response $\mathrm{e}^{21}$. However, older patients have a high incidence of neurologic complications, including cerebellar toxicity, after high-dose cytarabine treatment, limiting its use in this population.

Recently, the incorporation of alkylating agents with BBB penetration has been studied with good results. Temozolomide, an oral alkylating agent already used for glioblastoma, has shown high response rates even in patients with refractory or relapsed disease after high dose of $\mathrm{MTX}^{22,23}$. Prospective trials evaluating temozolomide as first line treatment for this entity are under way.

\section{Radiotherapy might be more harmful than beneficial}

Historically, radiotherapy (RTx) alone has been the standard treatment. Primary CNS lymphoma is a radiosensitive tumor and the whole brain should be irradiated, since a high incidence of relapses outside the radiation field has been observed. Doses of 40-50 Gy are considered the standard in primary CNS lymphoma, although studies using lower doses have shown similar results ${ }^{24}$.

Nowadays, RTx is used in two main situations: as palliative treatment, in patients not fit to receive chemotherapy, and as consolidation after high doses of $\mathrm{MTX}^{25}$. However, a high incidence of neurotoxicity has been reported in patients receiving radiotherapy, mostly in patients older than 65 years. Up to $35 \%$ of patient will present with neurologic deterioration after radiotherapy, leading to a mortality rate of $30 \%$ in 5 years ${ }^{26}$. A recent progress is the establishment of a panel of neuropsychological tests to assess, quantify and follow-up treatment-related neurologic deterioration in patients with primary CNS lymphoma. Attention, executive function, memory and psychomotor speed are the most commonly affected functions.

For these reasons, strategies to minimize neurotoxicity have been studied in recent years: 1) avoiding postchemotherapy WBRT in patients with complete response after chemotherapy; 2) delivering lower intensity WBRT and 3) replacing consolidation radiotherapy by other treatment. Avoiding post-chemotherapy WBRT in patients with CR after chemotherapy has been studied in a recent phase III prospective trial, and although the data is not definitive, there was no difference in $\mathrm{OS}^{25}$.

Replacing radiotherapy with other treatments is an alternative that has also been studied, and in this setting, high dose chemotherapy with autologous stem cell transplantation 
(ASCT) is still the best approach. In a pilot study involving 13 patients, a German Group obtained encouraging results (3-year DFS and OS:77\%) in patients receiving HD-MTX followed by ASCT without WBRT, so further investigation should be considered ${ }^{27}$. For now, ASCT remains the standard for relapsed/refractory disease after induction with HD-MTX.

In conclusion, PCNSL is a rare disease with complex management. Neurologists and neurosurgeons must be familiar with basic strategies and the sequential steps in planning the adequate treatment. More importantly, neurologists and neurosurgeons must give importance to the initial handling of a patient with suspected primary CNS lymphoma aiming at an early diagnosis and treatment.

\section{ACKNOLEDGEMENTS}

Suzana Maria Fleury Malheiros

\section{References}

1. Ferreri AJ, Abrey LE, Blay JY, et al. Summary statement on primary central nervous system lymphomas from the eighth international conference on malignant lymphoma, Lugano, Switzerland, June 12 to 15, 2002. J Clin Oncol 2003;21:2407-2414.

2. Rubenstein J, Ferreri AJ, Pittaluga S. Primary lymphoma of the central nervous system: epidemiology, pathology and current approaches to diagnosis, prognosis and treatment. Leuk Lymphoma 2008;49(Suppl 1):S43-S51.

3. Bataille B, Delwail V, Menet E, et al. Primary intracerebral malignant lymphoma: Report of 248 cases. J Neurosurg 2000;92:261-266.

4. Hoffman S, Propp JM, McCarthy BJ. Temporal trends in incidence of primary brain tumors in the United States, 1985-1999. Neuro Oncol 2006;8:27.

5. Schabet M Epidemiology of primary CNS lymphoma. J Neurooncol 1999;43:199.

6. Ferreri AJ, Blay JY, Reni M, et al. Prognostic scoring system for primary CNS lymphomas: the international extranodal lymphoma study group experience. J Clin Oncol 2003;21:266-272.

7. Vitolo U, Chiappella A, Ferreri AJ, et al. First-line treatment for primary testicular diffuse large B-cell lymphoma with rituximab-CHOP, CNS prophylaxis, and contralateral testis irradiation: final results of an international phase II trial. J Clin Oncol 2011;29:2766-2772.

8. Villa D, Connors JM, Sehn LH, Gascoyne RD, Savage KJ. Diffuse large B-cell lymphoma with involvement of the kidney: outcome and risk of central nervous system relapse. Haematologica 2011;96:1002-1007.

9. Ferreri AJ, Marturano E. Primary CNS lymphoma. Best Pract Res Clin Haematol 2012;25:119-130.

10. Fischer L, Martus P, Weller M, et al. Meningeal dissemination in primary CNS lymphoma: prospective evaluation of 282 patients. Neurology 2008;71:1102-1108.

11. Grimm SA, McCannel CA, Omuro AM, et al. Primary CNS lymphoma with intraocular involvement: International PCNSL Collaborative Group Report. Neurology 2008;71:1355.

12. Bromberg JE, Siemers MD, Taphoorn MJ. Is a "vanishing tumor" always a lymphoma? Neurology 2002;59:762-764.

13. Abrey LE, Batchelor TT, Ferreri AJ, et al. Report of an international workshop to standardize baseline evaluation and response criteria for primary CNS lymphoma.J Clin Oncol 2005;23:5034-5043.

14. Okita Y, Narita Y, Miyakita Y, et al. Long-term follow-up of vanishing tumors in the brain: How should a lesion mimicking primary CNS lymphoma be managed? Clin Neurol Neurosurg 2012;114:1217-1221.
15. Reni M, Ferreri AJ, Garancini MP, Villa E. Therapeutic management of primary central nervous system lymphoma in immunocompetent patients: results of a critical review of the literature. Ann Oncol 1997;8:227-234.

16. Ferreri AJ, Marturano E. Primary CNS lymphoma. Best Pract Res Clin Haematol 2012;25:119-130.

17. Lippens RJ, Winograd B. Methotrexate concentration levels in the cerebrospinal fluid during high-dose methotrexate infusions: an unreliable prediction. Pediatr Hematol Oncol 1988;5:115-124.

18. Ferreri AJ, Guerra E, Regazzi M, et al. Area under the curve of methotrexate and creatinine clearance are outcomedetermining factors in primary CNS lymphomas. Br J Cancer 2004;90:353-358.

19. Tetef ML, Margolin KA, Doroshow JH, et al. Pharmacokinetics and toxicity of high-dose intravenous methotrexate in the treatment of leptomeningeal carcinomatosis. Cancer Chemother Pharmacol 2000;46:19-26.

20. Ferreri AJ. How I treat primary CNS lymphoma. Blood 2011; 118:510-522.

21. Ferreri AJ, Reni M, Foppoli M, et al. High-dose cytarabine plus highdose methotrexate versus high-dose methotrexate alone in patients with primary CNS ymphoma: a randomised phase 2 trial. Lancet 2009;374:1512-1520

22. Reni M, Zaja F, MasonW, et al. Temozolomide as salvage treatment in primary brain lymphomas. Br J Cancer 2007;96:864-867.

23. Omuro AM, Taillandier $L$, Chinot $O$, et al. Temozolomide and methotrexate for primary central nervous system lymphoma in the elderly. J Neurooncol 2007;85:207-211.

24. Ferreri AJ, Verona C, Politi L, et al. Consolidation radiotherapy in primary CNS lymphomas: impact on outcome of different fields and doses in patients in complete remission after upfront chemotherapy. Int J Radiat Oncol Biol Phys 2011;80:169-175.

25. Thiel E, Korfel A, Martus P, et al. High-dose methotrexate with or without whole brain radiotherapy for primary CNS lymphoma (G-PCNSL-SG-1): a phase 3, randomised, non-inferiority trial. Lancet Oncol 2010;11:1036-1047.

26. Abrey LE, DeAngelis LM, Yahalom J. Long-term survival in primary CNS lymphoma.J Clin Oncol 1998;16:859-863.

27. Illerhaus G, Muller F, Feuerhake F, et al. High-dose chemotherapy and autologous stem-cell transplantation without consolidating radiotherapy as first-line treatment for primary lymphoma of the central nervous system. Haematologica 2008;93:147-148. 